HIAS-E-90

\title{
The Great Moderation: Updated Evidence with Joint Tests for Multiple Structural Changes in Variance and Persistence
}

\author{
${\text { Pierre } \operatorname{Perron}^{(a)} \text { and Yohei Yamamoto }}^{(b)}$
}

(a) Department of Economics, Boston University, 270 Bay State Rd., Boston, MA, 02215

(b) Department of Economics, Hitotsubashi University, 2-1 Naka, Kunitachi, Tokyo Japan, 186-8601

September, 2019

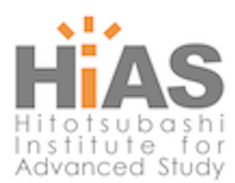

Hitotsubashi Institute for Advanced Study, Hitotsubashi University 2-1, Naka, Kunitachi, Tokyo 186-8601, Japan

tel:+81 425808604 http://hias.hit-u.ac.jp/

HIAS discussion papers can be downloaded without charge from: http://hdl.handle.net/10086/27202

https://ideas.repec.org/s/hit/hiasdp.html

All rights reserved. 


\title{
The Great Moderation: Updated Evidence with Joint Tests for Multiple Structural Changes in Variance and Persistence
}

\author{
Pierre Perron* \\ Yohei Yamamoto ${ }^{\dagger}$ \\ Boston University \\ Hitotsubashi University
}

September 16, 2019

\begin{abstract}
We assess the empirical evidence about the Great Moderation using a comprehensive framework to test for multiple structural changes in the coefficients and in the variance of the error term of a linear regression model provided by Perron, Yamamoto, and Zhou (2019). We apply it to U.S. real GDP and its major components for the period 1960:1 to 2018:4. A notable feature of our approach is that we adopt an unobserved component model, allowing for two breaks in the trend function in 1973:1 and 2008:1, in order to obtain a stationary or cyclical component modelled as an autoregressive process. First, we confirm evidence about the Great Moderation, i.e., a structural change in variance of the errors in the mid-80s for the various series. Second, additional breaks in variance are found in 1970:3 for GDP and production (goods), after which the sample standard deviation increased by three times. Hence, a part of the Great Moderation can be viewed as a reversion to the pre-70s level of volatility. Third, the evidence about systematic changes in the sum of the autoregressive coefficients (a measure of persistence) is weak over the whole sample period. Finally, we find little evidence of structural changes occurring in both the variance and the coefficients following the Great Recession (2007-2008). These results support views emphasizing the "good luck" hypothesis as a source of the Great Moderation, which continues even after the Great Recession.
\end{abstract}

JEL Classification Numbers: C22, C32

Keywords: the Great Moderation; the Great Recession; multiple structural changes; joint tests; structural change; trend-cycle decomposition.

\footnotetext{
*Department of Economics, Boston University, 270 Bay State Rd., Boston, MA, 02215 (perron@bu.edu).

${ }^{\dagger}$ Department of Economics, Hitotsubashi University, 2-1 Naka, Kunitachi, Tokyo Japan, 186-8601 (yohei.yamamoto@econ.hit-u.ac.jp).
} 


\section{Introduction}

One of the striking empirical facts in the U.S. economy is the presence of a sharp decline of macroeconomic volatility in the mid-80s, the so-called Great Moderation. Blanchard and Simon (2001) documented that the sample standard deviation of quarterly real GDP growth rates, i.e., the logarithmic first-differences, declined by half after the mid-80s. More formal statistical results were provided by Kim and Nelson (1999), who allowed a one-time structural change in the mean and the variance at the same (unknown) time in a Markov-switching model. They applied it to the real GDP growth rates and showed evidence of a decline in the mean gaps between booms and recessions starting in 1984:1. McConnell and Perez-Quiros (2000) used a two step testing procedure for real GDP growth, i.e., fitting some conditional mean model and then testing for a structural break in the mean of the absolute value of the residuals. Using the single structural break tests proposed by Andrews (1993) and Andrews and Ploberger (1994), they claimed evidence of a structural break in 1984:1 in the variance of the errors. Stock and Watson (2002) used a single structural change test for a break at some unknown date applied to the conditional mean of an autoregressive model (AR) of order 4 and subsequently applied the same test to the mean of the absolute residuals. They investigated 168 U.S. macroeconomic variables, detrended mostly via logarithmic first-differences (growth rates), and found that aggregate output as well as employment, consumption and sectorial output showed structural changes in the error variance in the mid-80s.

One issue which has important policy implications is that a decline in the unconditional variance of an observed series can be ascribed partly to a decline in the propagation dynamics (the persistence of the shocks) and partly to that of the variance of the shocks themselves. If one adopts an AR model specification, the former is represented by a structural change in the AR coefficients and the latter pertains to a change in the variance of errors. In the literature, the former type of change is usually viewed as supporting the hypothesis of "improved monetary policy" as a source of the Great Moderation (Clarida, Gali and Gertler, 2000, Cogley and Sargent, 2001, Bernanke, 2004, Herrera and Pesavento, 2005, Gali and Gambetti, 2009), while the latter type of change is perceived as emphasizing the "good luck" hypothesis (Stock and Watson, 2002, Ahmed, Levin and Wilson, 2004, Sensier and van Dijk, 2004, Sims and Zha, 2006), although the conclusions of these studies are often ambivalent. Another hypothesis pertains to production smoothing achieved by better inventory management that occurred in the durable manufacturing industries (Ramey and Vine, 2006, Herrera and Pesavento, 2005, Stiroh, 2009, Morley and Singh, 2016). Summers 
(2005) and Benati (2008) documented international evidence about the Great Moderation. Also of interest is the fact that changes in the variance of structural shocks in a constant coefficients setting can be used as a tool to identify simultaneous equation systems (Rigobon, 2003, Lanne and Lütkepohl, 2008).

Of more recent interest is a debate as to whether the Great Moderation ended due to the financial crisis of 2007-08, i.e., the Great Recession. Clark (2009) documented a significant rise in macroeconomic volatility and claimed that it overturned the Great Moderation. Blanchard (2014) suggested that a benign view of economic fluctuation until 2008 needed to be reassessed. Stock and Watson (2017) argued that the low-volatility period lasted through 2007 after which the economy seems to have returned to a higher volatility regime. Taylor (2011) pointed out that macroeconomic policies were deviating from the standard rules, arguing that such deviations ended the Great Moderation and fostered the Great Recession. On the other hand, Gadea et al. (2018) found that output volatility remained subdued even after the Great Recession, applying a two step testing procedure for structural changes in the conditional mean and variance similar to that of McConnell and Perez-Quiros (2000) for GDP growth from 1953:1 to 2014:3. ${ }^{1}$ Gadea et al. (2019) used historical data of U.S. GDP growth from 1875:1 to 2014:2 and reached a similar conclusion.

In this paper, we investigate the aforementioned problems using multiple structural change tests proposed by Perron, Yamamoto and Zhou (2019); henceforth PYZ. They provided a comprehensive treatment to jointly test for multiple structural changes in the unconditional variance of the errors and the parameters of the conditional mean in a linear regression model. They proposed quasi likelihood ratio tests building on the work of $\mathrm{Qu}$ and Perron (2007). In particular, their framework provides (a) tests for given number of changes in regression coefficients and variance of the errors; (b) tests for some unknown number of changes within some pre-specified maximum; (c) tests for changes in variance (coefficients) allowing for a given number of changes in the coefficients (variance); (d) sequential procedures to estimate the number of changes in the coefficients and in the variance. This framework has clear benefits to detect multiple structural changes in the coefficients and in the variance, compared to the two-step testing procedure commonly used in the literature (McConnell and Perez-Quiros, 2000, Stock and Watson, 2002, Herrera and Pesavento, 2005, Gadea et al., 2018). This is so because testing for mean breaks ignoring variance breaks

\footnotetext{
${ }^{1}$ They also complemented their results using the same method as ours but allowing only for a maximum of one change in each of the parameters of the conditional mean and the variance of the errors under the null hypothesis.
} 
induces a power loss and testing for variance breaks ignoring mean breaks yields tests with important size distortions. See Perron and Yamamoto (2019) for extensive simulation results.

Almost all existing studies use the logarithmic first-differences of the original series. However, this is a filter that affects the spectrum of the series in different ways at different frequencies and, hence, may downplay low frequency variabilities. We instead use a trendcycle decomposition based on an unobserved component model allowing two breaks in the slope of the trend component in 1973:1 and 2008:1. This is in the spirit of Perron and Wada (2009) who showed that, for U.S. real GDP data from 1947:1 to 1998:2, allowing for a break in the trend function in 1973:1 yields a cyclical component that captures the NBER business cycle chronologies of recessions and expansions very well. Our framework is a simple extension of their methods by allowing an additional break in 2008:1. This also reduces the risk that the structural change tests are biased due to small shifts in the mean of the first-differenced series, which allows us to focus more precisely on the issue of changes in the variance of the shocks versus changes in the persistence of the series. It also allows avoiding problems of inference when the first-differenced series have a noise component that is over-differenced. As in Perron and Wada (2009), our resulting cyclical component captures the NBER business cycle chronologies of recisions and expansions very well.

The rest of the paper is structured as follows. Section 2 outlines the econometric methods used and the multiple structural change tests proposed by PYZ. Section 3 describes the data used and the detrending method applied to have a stationary component. Section 4 presents the results and discusses their relevance. Section 5 provides brief concluding comments.

\section{Econometric Methods}

We consider an autoregressive model in which $m$ breaks are allowed in the coefficients of the conditional mean and the variance of the errors:

$$
y_{t}=x_{t} \beta+z_{t} \delta_{j}+e_{t}, \quad t=T_{j-1}^{c}+1, \ldots, T_{j}^{c},
$$

for $j=1, \ldots, m+1$. This is a partial structural change model in which the coefficients associated with the regressors $z_{t}$ (a vector of dimension $q$ ) change at the break dates $\left(T_{1}^{c}, \ldots, T_{m}^{c}\right.$ ), which are treated as unknown, with the convention $T_{0}^{c}=0$ and $T_{m+1}^{c}=T$. The $n$ breaks in the variance of errors $e_{t}$ occur at the unknown dates $\left(T_{1}^{v}, \ldots, T_{n}^{v}\right)$. Accordingly, $e_{t}$ has zero mean and variance $\sigma_{i}^{2}$ for $T_{i-1}^{v}+1 \leq t \leq T_{i}^{v}$ with $i=1, \ldots, n+1$, again with $T_{0}^{v}=0$ and $T_{n+1}^{v}=T$. The breaks in the variance and in the coefficients may happen at different times or may overlap partly or completely. 
We consider three sets of testing problems (TPs). The first pertains to testing for given number of changes in coefficients and variance: TP-1: $H_{0}:\{m=n=0\}$ versus $H_{1}:\{m=0$, $\left.n=n_{a}\right\}$; TP-2: $H_{0}:\left\{m=m_{a}, n=0\right\}$ versus $H_{1}:\left\{m=m_{a}, n=n_{a}\right\}$; TP-3: $H_{0}:\{m=$ $\left.0, n=n_{a}\right\}$ versus $H_{1}:\left\{m=m_{a}, n=n_{a}\right\}$; TP-4: $H_{0}:\{m=n=0\}$ versus $H_{1}:\left\{m=m_{a}\right.$, $\left.n=n_{a}\right\}$, where $m_{a}$ and $n_{a}$ are some positive numbers selected a priori. In the second set, we consider testing for an unknown number of changes within some pre-specified maximum: TP-5: $H_{0}:\{m=n=0\}$ versus $H_{1}:\{m=0,1 \leq n \leq N\}$; TP-6: $H_{0}:\left\{m=m_{a}, n=0\right\}$ versus $H_{1}:\left\{m=m_{a}, 1 \leq n \leq N\right\}$; TP-7: $H_{0}:\left\{m=0, n=n_{a}\right\}$ versus $H_{1}:\{1 \leq$ $\left.m \leq M, n=n_{a}\right\}$; TP-8: $H_{0}:\{m=n=0\}$ versus $H_{1}:\{1 \leq m \leq M, 1 \leq n \leq N\}$. Finally, sequential procedures to estimate the number of changes are considered via TP-9: $H_{0}:\left\{m=m_{a}, n=n_{a}\right\}$ versus $H_{1}:\left\{m=m_{a}+1, n=n_{a}\right\}$; TP-10: $H_{0}:\left\{m=m_{a}, n=n_{a}\right\}$ versus $H_{1}:\left\{m=m_{a}, n=n_{a}+1\right\}$. These are useful to assess the adequacy of a model with a particular number of breaks by looking at whether including one more break is warranted.

Building on the work of $\mathrm{Qu}$ and Perron (2007), PYZ provided a quasi-likelihood ratio supremum-type test for each testing problem. Denote the Gaussian log-likelihood of the linear regression model by $l_{T}$ under $\{m=0, n=0\}, l_{T}\left(T_{1}^{v}, \ldots, T_{n}^{v}\right)$ under $\{m=0, n \neq 0\}$, $l_{T}\left(T_{1}^{c}, \ldots, T_{m}^{c}\right)$ under $\{m \neq 0, n=0\}$, and $l_{T}\left(T_{1}^{c}, \ldots, T_{m}^{c} ; T_{1}^{v}, \ldots, T_{n}^{v}\right)$ under $\{m \neq 0, n \neq 0\}$ (see PYZ for the exact expressions). To obtain the break dates, we maximize the log-likelihood function using a trimming $[\varepsilon T]$ for the admissible candidate break dates, where $\varepsilon$ is some small positive constant fraction. Note that we denote the estimates of the break dates in coefficients and variance by a " " when they are obtained jointly and by a "^" when they are obtained separately. Then, the test statistics for TP-1 to TP-4 are:

$$
\begin{aligned}
& (\mathrm{TP}-1) \quad \operatorname{SupLR}_{1, T}(n)=2\left[l_{T}\left(\hat{T}_{1}^{v}, \ldots, \hat{T}_{n}^{v}\right)-l_{T}\right], \\
& (\mathrm{TP}-2) \operatorname{SupLR}_{2, T}(n \mid m)=2\left[l_{T}\left(\widetilde{T}_{1}^{c}, \ldots, \widetilde{T}_{m}^{c} ; \widetilde{T}_{1}^{v}, \ldots, \widetilde{T}_{n}^{v}\right)-l_{T}\left(\hat{T}_{1}^{c}, \ldots, \hat{T}_{m}^{c}\right)\right] \text {, } \\
& (\mathrm{TP}-3) \quad \operatorname{SupLR}_{3, T}(m \mid n)=2\left[l_{T}\left(\widetilde{T}_{1}^{c}, \ldots, \widetilde{T}_{m}^{c} ; \widetilde{T}_{1}^{v}, \ldots, \widetilde{T}_{n}^{v}\right)-l_{T}\left(\hat{T}_{1}^{v}, \ldots, \hat{T}_{n}^{v}\right)\right] \text {, } \\
& (\mathrm{TP}-4) \operatorname{SupLR}_{4, T}(m, n)=2\left[l_{T}\left(\widetilde{T}_{1}^{c}, \ldots, \widetilde{T}_{m}^{c} ; \widetilde{T}_{1}^{v}, \ldots, \widetilde{T}_{n}^{v}\right)-l_{T}\right] \text {, }
\end{aligned}
$$

and, for TP-5 to TP-8, the corresponding UDmax type tests of Bai and Perron (1998) are:

$$
\begin{aligned}
(\mathrm{TP}-5) U \operatorname{Dmax}_{1, T}(N) & =\max _{1 \leq n \leq N} n^{-1} \operatorname{SupLR}_{1, T}(n), \\
(\mathrm{TP}-6) U \operatorname{Dmax}_{2, T}(N \mid m) & =\max _{1 \leq n \leq N} n^{-1} \operatorname{SupLR}_{2, T}(n \mid m), \\
(\mathrm{TP}-7) U \operatorname{Dmax}_{3, T}(M \mid n) & =\max _{1 \leq m \leq M} m^{-1} \operatorname{SupLR}_{3, T}(m \mid n), \\
(\mathrm{TP}-8) U \operatorname{Dmax}_{4, T}(M, N) & =\max _{1 \leq m \leq M 1 \leq n \leq N} \max _{1}(m+n)^{-1} \operatorname{SupLR}_{4, T}(m, n),
\end{aligned}
$$


PYZ showed that, for all tests except for TP-4 and TP-8, one can use the critical values provided by Bai and Perron (1998), while those of the tests for TP-4 and TP-8 are provided in PYZ with $M$ and $N$ up to 2. Here, we provide additional critical values for $M$ and $N$ up to 3. Those for the $\operatorname{SupLR}_{4, T}$ and $U D \max _{4, T}$ tests of size $1 \%, 2.5 \%, 5 \%$ and $10 \%$ are presented in Table 1 for $q$ between 1 and 5 with the truncation parameter $\varepsilon=0.10$. Results are also provided for $(M, N)=(3,2)$ and $(2,3)$ with $\varepsilon=0.15$. The critical values are obtained via simulations of the limit distributions obtained in PYZ with the Wiener processes approximated by the partial sums of $i . i . d$. standard normal random variables with 1,000 discrete steps and 10,000 replications.

TP-9 and TP-10 are used to select the number of breaks in coefficients (intercept and autoregressive parameters) and in variance. When selecting the number of coefficient breaks, we consider TP-9 and the test $\operatorname{SupLR}_{9, T}(m+1 \mid m, N)$ is applied (see PYZ for the exact expressions), starting with $H_{0}: m=0$ and $H_{1}: m=1$, where $N=3$. Upon a rejection, we proceed to $H_{0}: m=1$ and $H_{1}: m=2$, and so on until the test stops rejecting. Similarly, to select the number of breaks in the variance, TP-10 is considered and the test $\operatorname{SupLR}_{10, T}(n+1 \mid M, n)$ with $M=3$ is used for $n=0,1, \ldots$ until a non-rejection occurs.

\section{Data and detrending method}

We use seasonally-adjusted quarterly US real GDP and its major components: consumption, investment, exports, imports and government spending, covering the period 1947:1 to 2018:4. We also use the components of real GDP by major products: production (goods), production (services) and production (structures). A logarithmic transformation is applied to the raw data and then multiplied by 100 . To eliminate the trend component we use the following unobserved component model (Clark, 1987, Morley, Nelson and Zivot, 2003, Perron and Wada, 2009):

$$
y_{t}=\tau_{t}+c_{t} ; \tau_{t}=\mu_{t}+\tau_{t-1}+\eta_{t} ; \phi(L) c_{t}=\varepsilon_{t}
$$

where $\tau_{t}$ is the trend component, $c_{t}$ is the cyclical component and $\phi(L)$ is either an $\operatorname{AR}(1)$ or $\operatorname{AR}(2)$ lag-polynomial, i.e., $\phi(L)=1-\phi_{1} L-\phi_{2} L^{2}$, with $L$ the usual lag operator. The $\operatorname{AR}(2)$ specification is adopted for all series except consumption, investment and production (services), for which the $\mathrm{AR}(1)$ specification is preferred. The shocks are specified by

$$
\left[\begin{array}{l}
\eta_{t} \\
\varepsilon_{t}
\end{array}\right] \sim \text { i.i.d.N }\left(\left[\begin{array}{l}
0 \\
0
\end{array}\right],\left[\begin{array}{cc}
\sigma_{\eta}^{2} & \sigma_{\eta \varepsilon} \\
\sigma_{\eta \varepsilon} & \sigma_{\varepsilon}^{2}
\end{array}\right]\right),
$$


where $\sigma_{\eta \varepsilon}=0$ is assumed; specifying a non-zero value leads to similar results. We follow Perron and Wada (2009) who showed that, using the US real GDP from 1947:1-1998:2, if a change in the slope of the trend is accounted for in 1973:1, the method yields a cyclical component which accords very well with the NBER chronology of recessions and expansions and it leaves little variation, if any, to the trend component. Since our sample period includes the Great Recession, we allow for an additional break in 2008:1 so that

$$
\mu_{t}=\mu+d_{1} I(t>1973: 1)+d_{2} I(t>2008: 1) .
$$

The model is estimated via the standard Kalman filter algorithm. Figure 1 presents graphs of a) the original series and the fitted trend (left panels) and b) the deviations of the original series from trend, or cyclical components (right panels). The parameter estimates ${ }^{2}$ are reported in Table 2. What is important is that for all series, except "Government spending", the estimate of $\sigma_{\eta}^{2}$ is 0 . Hence, all the source of variability is contained in the cyclical component, which is indeed nearly identical to the residuals from a piecewise linearly detrended series with changes in slope in 1973:1 and 2008:1. Note that Luo and Startz (2014) allowed a trend break in 2006:1 and obtained a characterization similar to that of Perron and Wada (2009). Our results are robust to alternative choices for the second break date; e.g., 2006:1 or 2008:1, because it only affects the timing when the cyclical component is perceived as becoming above trend. Both estimates of $d_{1}$ and $d_{2}$ are negative. The first relates to the well document productivity slowdown that occurred in 1973. The second decrease in slope in 2008:1 is more contentious but of no consequence for our analysis. Without it, the cyclical component is basically flat suggesting the absence of a recovery or expansion, contrary to what is widely perceived to have happened. With the decrease in slope, the cyclical component shows a clear upward trend that is consistent with an expansion. We prefer the latter characterization. It indicates that an expansion has indeed occurred but with respect to a lower long-term trend, i.e., a very slow recovery as the last 10 years have been commonly characterized. In any event, since the variance of the noise around the trend, $\sigma_{\eta}^{2}$, is null, none of our results about the variability and persistence of the cyclical component is affected by this modeling choice. It is basically a matter of labeling the post-2008 period as a slow "below trend expansion" or an "above smaller trend expansion".

Using our approach to obtain a stationary component has several advantages over the commonly used application of using the logarithmic first-differences, i.e., the growth rates.

\footnotetext{
${ }^{2}$ The standard errors reported are the diagonal elements of the negative inverse of the empirical Hessian of the log likelihood function obtained from the MATLAB version R2019a solver (fminunc function in their optimization toolbox).
} 
First, first-differencing is a filter that affects the spectrum of the series in different ways at different frequencies. It may downplay changes in variability at low frequency. Second, when applying the structural change tests, the trend breaks may be difficult to capture as first-differencing translates them into small changes in mean. Testing for such changes in mean becomes problematic because the first-differences involves a resulting series with an over-differenced noise. Third, the unobserved component model shows that the resulting noise is at least mean stationary, so that it will not bias the tests and allow us to focus on changes in persistence and variance. Fourth, the series looks much more like a cyclical component which accords well with the NBER chronology of expansions and recessions.

Note that for "Government spending" one should also consider possible changes in the variance of $\eta_{t}$ since the estimate of $\sigma_{\eta}^{2}$ is non-zero. We obtained an estimate of $\eta_{t}$ as the first-differences of the smoothed estimates of $\tau_{t}$ from which we subtracted the estimate of $\mu_{t}$. A plot of this estimate is presented in Figure 2 along with the estimate of the cyclical component $c_{t}$. It is evident that the magnitude of the former is negligible compared to the latter. Hence, any issue of changes in the variance of $\eta_{t}$ will be negligible compared to changes occurring in $c_{t}$. Hence, we shall only consider $c_{t}$ for "Government spending", as we do for the other series, without loss of substance.

\section{Results of multiple structural change tests}

We now present the main results; those for the structural change tests in Section 4.1 and the estimates of the break dates and parameter estimates in Section 4.2. Throughout, we consider a simple autoregressive model of order $4, \operatorname{AR}(4)$, with a fitted intercept. Hence, in terms of model $(1), x_{t}$ is null and $z_{t}=\left[1, y_{t-1}, y_{t-2}, y_{t-3}, y_{t-4}\right]$. We include a constant as parts of the regressors whose coefficients are subject to change in order to assess whether any change in mean is left in the cyclical components when using our detrending procedure with two breaks in 1973:1 and 2008:1. It also serves as a diagnostic check to assess the adequacy of allowing breaks at these dates. We also use an AR(4) specification even though our unobserved components model specifies a cyclical component with either an $\operatorname{AR}(2)$ or $\mathrm{AR}(1)$ structure. This is done to ensure that any remaining correlation is taken into account. It involves no loss in generality or precision as the AR(4) model is encompassing and that we mainly focus on the sum of the autoregressive coefficients as a measure of persistence. We start the sample from 1960:1, consistent with Stock and Watson (2002) although the data are available from 1947, because including the 1950s makes the results sensitive to the starting date, possibly because of the inclusion of the Korean War period. 


\subsection{Presence of structural changes}

Our first results, presented in Table 3, pertain to testing if there is evidence for at least some breaks by using the $S u p L R_{4, T}$ test with $m_{a}$ and $n_{a}$ ranging from 1 to 3 and the $U D \max _{4, T}$ test with $M=N=3$ (using, here and throughout all results, the truncation parameter $\varepsilon=0.10)$. These tests are complementary. The $S u p L R_{4, T}$ is directed at having maximal power for the pre-specified number of break, though they still have power when the number of breaks is misspecified, whether in the variance or in the coefficients. The $U D \max _{4, T}$ aims at testing for any numbers of breaks within the pre-specified upper bounds. As in Bai and Perron $(1998,2003)$, these are very useful because the power is usually as good as the test with the correct number of breaks. They are, however, less informative as one can only conclude that at least one break in either the coefficients or the variance has occurred. Both tests are a good starting point to assess whether breaks are present. As shown in Table 3 , we find evidence for at least some breaks in consumption, exports, imports, government spending and production (services) as the $U D \max _{4, T}$ test rejects at the $5 \%$ level for these series. We find less clear evidence for GDP, investment, production (goods) and production (structures) as some of the $S u p L R_{4, T}$ tests reject but not the $U D \max _{4, T}$ test at the $10 \%$ level. For series with a clear rejection, it is useful to compute a wide range of tests to decide which model to select. For series with a weaker or no rejection, it may be the case that the tests lack power if only changes in the variance or in the coefficients occur. Hence, we also use other tests to narrow down the types of breaks present.

Table 4 reports results when testing for multiple structural changes in the variance conditional on changes in the coefficients occurring (including zero change). We allow for up to 3 changes in the coefficients (i.e., $m_{a}=0,1,2$ or 3 ) when testing for such variance breaks. These tests have the right size for all values of $m_{a}$ but, of course, are more powerful when the correct number of breaks is used. The tests used are then the $S u p L R_{1, T}$ test for $n_{a}=0$ and the $\operatorname{Sup} L R_{2, T}$ test for $n_{a}=1,2$ and 3. For an unspecified number of changes in coefficients within a maximal value $N=3$, the $U D \max _{2, T}$ test is used to test for $m_{a}$ changes in coefficients with $m_{a}=0,1,2,3$. The results show that the latter test rejects the null hypothesis of no variance break for a broad set of variables; in particular, for consumption, exports, imports, government spending and production (services). These are consistent with the results obtained with the $U D \max _{4, T}$ tests. In addition, rejections also occur for GDP and production (goods), and to a lesser extent for production (structures) and for investment (higher p-values and/or results more sensitive to the choice of $m_{a}$ ). Overall, the results show widespread evidence of structural changes in the variance of errors. 
To select the number of structural changes in the variance, we adopt a sequential procedure using the SupL $R_{10, T}$ test with $m_{a}=3$ and a $10 \%$ significant level when testing for $n_{a}$ versus $n_{a}+1$ breaks in variance applied sequentially for $n_{a}=0,1,2,3$. The number of breaks selected is the value $n_{a}$ for which the test rejects but fails to reject for $n_{a}+1$. The results are presented in Table 5. We obtain two breaks in the variance for GDP and production (goods) and one break in the other series except that no variance break is detected in production (structures). It is important to ensure that the results of the sequential test comply with the previous testing results. Since Table 4 suggests evidence for structural breaks in the variance for all series, though with only marginal evidence for investment and production (structures), the number of breaks selected by the sequential procedure are adequate.

We now turn to changes in the coefficients. Table 6 provides results for the tests $S u p L R_{3, T}$ with $m_{a}=1,2,3$ and $U D \max _{3, T}$ with $M=3$. In both cases, we consider $n_{a}=0,1,2$ and 3 . The case with $m_{a}=1$ and $n_{a}=0$ reduces to the standard SupLR test for a change in the coefficients (Andrews, 1993). As explained above, two breaks in the trend component are allowed to obtain the cyclical component. Hence, our focus here is on testing for changes in persistence. Both tests show strong rejections under any specified number of breaks for exports and imports. However, for the other series, the results show weak, if any, evidence for changes in the parameters. This is confirmed in Table 7, which presents results for the sequential $S u p L R_{9, T}$ test to select the number of breaks in the coefficients with $n_{a}=3$. It suggests one break for exports and imports and no break for the other series.

\subsection{Break dates and parameter estimates}

We now present the estimates the break dates for the selected number of breaks in the variance and coefficients via jointly maximizing the likelihood function (Qu and Perron, 2007). We also provide point estimates of the segment-wise variance and the coefficients. In particular, the sample standard deviation as a ratio over that of the first regime and the sum of the autoregressive coefficients are reported. The confidence intervals for the break dates were obtained using Theorem 3 of Qu and Perron (2007) based on the Gaussian likelihood function with regimes segmented by the union of the variance and the coefficient breaks selected by the sequential procedure. The results in Tables 8 yield the following conclusions. First, consistent with the Great Moderation, structural changes in the variance are estimated in the mid-80s for GDP, investment, imports and production (goods). These break dates closely match those reported by Stock and Watson (2002), i.e. 1983:2 for GDP, 1986:2 for imports and 1983:4 for production (goods). Other break dates in variance are also consistent 
with their results such as 1992:1 for consumption. Second, however, our multiple break tests find additional breaks in variance in 1970:3 for GDP and production (goods), after which the sample standard deviation increased threefold. This finding suggests a partial reversal instead of a moderation, i.e., the presence of a temporary regime with a large variance in the 70s and early 80s. Hence, part of the Great Moderation can be viewed as a reversion to the pre 1970 volatility level. Third, we find little evidence of structural changes in the coefficients once the two breaks in the slope of the trend are accounted for. Finally, we find no evidence for structural changes in both the variance and the coefficients around the Great Recession. This result is consistent with those obtained by Gadea et al. (2018, 2019).

\section{Conclusion}

In this paper, we provided additional empirical evidence about the Great Moderation using a comprehensive framework to test for multiple structural changes in the coefficients and in the variance of error term of a linear regression model provided by Perron, Yamamoto and Zhou (2019). In particular, the framework provides methods to (a) test for given number of changes in regression coefficients and variance of the errors, (b) test for some unknown number of changes within some pre-specified maximum, (c) test for changes in variance (coefficients) allowing for a given number of changes in the coefficients (variance) and (d) sequential procedures to estimate the number of changes. We applied these methods to quarterly U.S. real GDP and its major components for the period 1960:1 to 2018:4. Unlike most related studies, we adopted an unobserved component model, allowing for two breaks in the slope of trend in 1973:1 and 2008:1. Our cyclical components are similar to the residuals obtained from a piecewise linear regression accounting for the two trend breaks. The method follows Perron and Wada (2009) to an extended sample period and, similar to their results, our detrended series follows closely the NBER chronology for recessions and expansions.

We obtained the following important empirical findings. First, we confirmed evidence for the Great Moderation, i.e., a structural change in the variance of the errors in the mid-80s for GDP, investment, imports and production (goods). Second, we found an additional break in variance at 1970:3 for GDP and production (goods), after which the sample standard deviation increased threefold. Hence, a part of the Great Moderation can be viewed as a reversion to the pre 1970 volatility level. Third, we found little evidence of structural change in the coefficients once the two breaks in the slope of the trend are accounted for. Finally, we found no evidence for changes in the variance nor in the coefficients around the Great Recession. Hence, the low volatility regime is still in effect. 


\section{References}

Andrews, D.W.K. (1993): "Tests for parameter instability and structural change with unknown change point," Econometrica 61, 821-856.

Andrews, D.W.K., and Ploberger, W. (1994): "Optimal tests when a nuisance parameter is present only under the alternative," Econometrica 62, 1383-1414.

Ahmed, S., Levin, A., and Wilson, B.A. (2004): "Recent U.S. macroeconomic stability: good policies, good practices, or good luck?" Review of Economics and Statistics 86, 824-832.

Bai, J., and Perron, P. (1998): "Estimating and testing linear models with multiple structural changes," Econometrica 66, 47-78.

Bai, J., and Perron, P. (2003): "Computation and analysis of multiple structural change models," Journal of Applied Econometrics 18, 1-22.

Benati, L. (2008): "The "Great Moderation" in the United Kingdom," Journal of Money, Credit, and Banking 40, 121-147.

Bernanke, B.S. (2004): "The Great Moderation," speech at the meetings of the Eastern Economic Association, Washington, DC, February 20, 2004. https://www. federalreserve.gov/boarddocs/speeches/2004/20040220/.

Blanchard, O., and Simon, J. (2001): "The long and large decline in U.S. output volatility," Brookings Papers on Economic Activity 1, 135-173.

Blanchard, O. (2014): "Where danger lurks," Finance and Development 51, 28-31.

Clarida, R., Gali, J., and Gertler, M. (2000): "Monetary policy rules and macroeconomic stability: evidence and some theory," Quarterly Journal of Economics 115, 147-180.

Clark, P.K., (1987): "The cycle component of the U.S. economic activity," Quartely Journal of Economics 102, 797-814.

Clark, T.E. (2009): "Is the great moderation over? an empirical analysis," Economic Review QIV, Federal Reserve Bank of Kansas, 5-42.

Cogley, T., and Sargent, T.J. (2001): "Evolving post-World War II U.S. inflation dynamics," NBER Macroeconomics Annual 16. B.S. Bernanke and K. Rogoff (eds). Cambridge, MIT Press, 331-373.

Gadea, M.D., Gómez-Loscos, A., and Pérez-Quirós, G. (2018): "Great moderation and great recession: From plain sailing to stormy seas?" International Economic Review 59, 2297-2321.

Gadea, M.D., Gómez-Loscos, A., and Pérez-Quirós, G. (2019): "The decline in volatility in the US economy. A historical perspective," Oxford Economic Papers, 1-23. 
Gali, J., and Gambetti, L. (2009): "On the sources of the great moderation," American Economic Journal: Macroeconomics 1, 26-57.

Herrera, A.M., and Pesavento, E. (2005): "The decline in U.S. output volatility: structural changes and inventory investment," Journal of Business 83 Economic Statistics 23, 462-472.

Kim, C.-J., and Nelson, C.R. (1999): "Has the U.S. economy become more stable? A Bayesian approach based on a Markov-switching model of the business cycle," Review of Economics and Statistics 81, 608-616.

Lanne, M., and Lütkepohl, H. (2008): "Identifying monetary policy shock via changes in volatility," Journal of Money, Credit, and Banking 40, 1131-1149.

Luo, S., and Startz, R. (2014): "Is it one break or ongoing permanent shocks that explains U.S. real GDP?" Journal of Monetary Economics 66, 155-163.

McConnell, M.M., and Perez-Quiros, G. (2000): "Output fluctuations in the United States: What has changed since the early 1980's?" American Economic Review 90, 1464-1476.

Morley, J.C., Nelson C.R., Zivot E. (2003): "Why are Beveridge-Nelson and unobservedcomponent decompositions of GDP so different?" Review of Economics and Statistics 85, 235-243.

Morley, J.C., and Singh, A. (2016): "Inventory shocks and the great moderation," Journal of Money, Credit and Banking 48, 699-728.

Perron, P., and Wada, T. (2009): "Let's take a break: trend and cycles in US real GDP," Journal of Monetary Economics 56, 749-765.

Perron, P., and Yamamoto, Y. (2019): "Pitfalls of two steps testing for changes in the error variance and coefficients of a linear regression models," Econometrics 7(2), 22.

Perron, P., and Yamamoto, Y., Zhou, J. (2019): "Testing jointly for structural changes in the error variance and coefficients of a linear regression model," Unpublished manuscript, Department of Economics, Boston University.

Qu, Z., and Perron, P. (2007): "Estimating and testing multiple structural changes in multivariate regressions," Econometrica 75, 459-502.

Ramey, V.A., and Vine, D.J. (2006): "Declining volatility in the US automobile industry," American Economic Review 96, 1876-1889.

Rigobon, R. (2003): "Identification through heteroskedasticity," Review of Economics and Statistics 85, 777-792.

Sensier, M., and van Dijk, D. (2004): "Testing for volatility changes in U.S. macroeconomic time series," Review of Economics and Statistics 86, 833-839. 
Sims, C., and Zha, T. (2006): "Were there regime switches in U.S. monetary policy?" American Economic Review 96, 54-81.

Stiroh, K.J. (2009): "Volatility accounting: A production perspective on increased economic stability," Journal of the European Economic Association 7, 671-696.

Stock, J.H., and Watson, M.W. (2002): "Has the business cycle changed and why?" in NBER Macroeconomics Annual 17, M. Gertler \& K. Rogoff (eds.), Cambridge, MIT Press, 159-218.

Stock, J.H., and Watson, M.W. (2017): "Twenty years of time series econometrics in ten pictures," Journal of Economic Perspectives 31(2), 59-86.

Summers, P.M. (2005): "What caused the Great Moderation? Some cross-country evidence," Economic Review QII, Federal Reserve Bank of Kansas, 5-32.

Taylor, J.B. (2011): "Macroeconomic lessons from the Great Deviation," in NBER Macroeconomics Annual 25. D. Acemoglu and M. Woodford (eds). 387-395. 


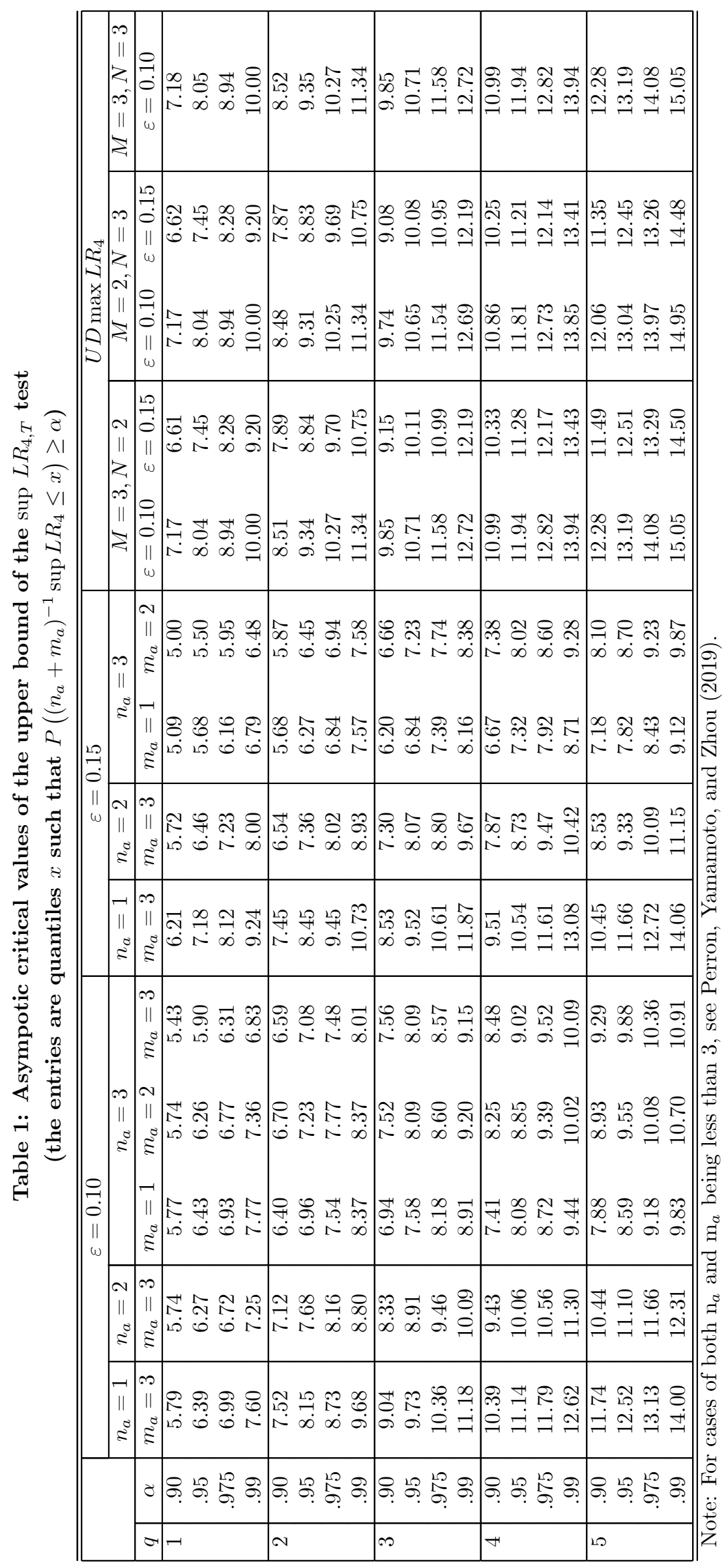


Table 2. Parameter estimates of the unobserved component model

\begin{tabular}{l|cccccccc}
\hline \hline & $\sigma_{\eta}$ & $\sigma_{\varepsilon}$ & $\mu$ & $d_{1}$ & $d_{2}$ & $\phi_{1}$ & $\phi_{2}$ & $l_{T}$ \\
\hline \hline GDP & 0.00 & 0.84 & 0.96 & -0.21 & -0.58 & 1.30 & -0.36 & 369.52 \\
Consumption & - & $(0.02)$ & $(0.03)$ & $(0.04)$ & $(0.07)$ & $(0.20)$ & $(1.17)$ & \\
& 0.00 & 0.77 & 0.97 & -0.16 & -0.51 & 0.96 & - & 346.39 \\
Investment & - & $(0.02)$ & $(0.03)$ & $(0.05)$ & $(0.08)$ & $(0.02)$ & - & \\
& 0.00 & 4.65 & 1.11 & -0.16 & -0.53 & 0.91 & - & 862.97 \\
Exports & - & $(0.00)$ & $(0.11)$ & $(0.16)$ & $(0.28)$ & $(0.02)$ & - & \\
& 0.00 & 3.12 & 1.52 & -0.03 & -0.83 & 0.76 & 0.18 & 614.62 \\
Imports & - & $(0.00)$ & $(0.19)$ & $(0.23)$ & $(0.27)$ & $(1.08)$ & $(1.60)$ & \\
Government Spending & 0.00 & 3.64 & 1.51 & 0.04 & -0.87 & 1.00 & -0.09 & 792.26 \\
Production (Goods) & - & $(0.00)$ & $(0.09)$ & $(0.13)$ & $(0.24)$ & $(0.36)$ & $(1.94)$ & \\
& 0.76 & 0.96 & 0.96 & -0.53 & -0.87 & 1.71 & -0.73 & 497.40 \\
Production (Services) & $0.073)$ & $(0.05)$ & $(0.13)$ & $(0.19)$ & $(0.31)$ & $(0.39)$ & $(2.07)$ & \\
Production (Structures) & 0.00 & 1.75 & 0.94 & 0.00 & -0.14 & 1.08 & -0.20 & 581.60 \\
& - & $(0.01)$ & $(0.03)$ & $(0.05)$ & $(0.10)$ & $(0.18)$ & $(0.93)$ & \multirow{2}{*}{309.47} \\
& 0.00 & 0.68 & 0.99 & -0.28 & -0.67 & 0.97 & - & $6.02)$ \\
\end{tabular}

Note: Standard errors in parentheses. When $\sigma_{\eta}=0$, they are not well-defined and thus unreported. 


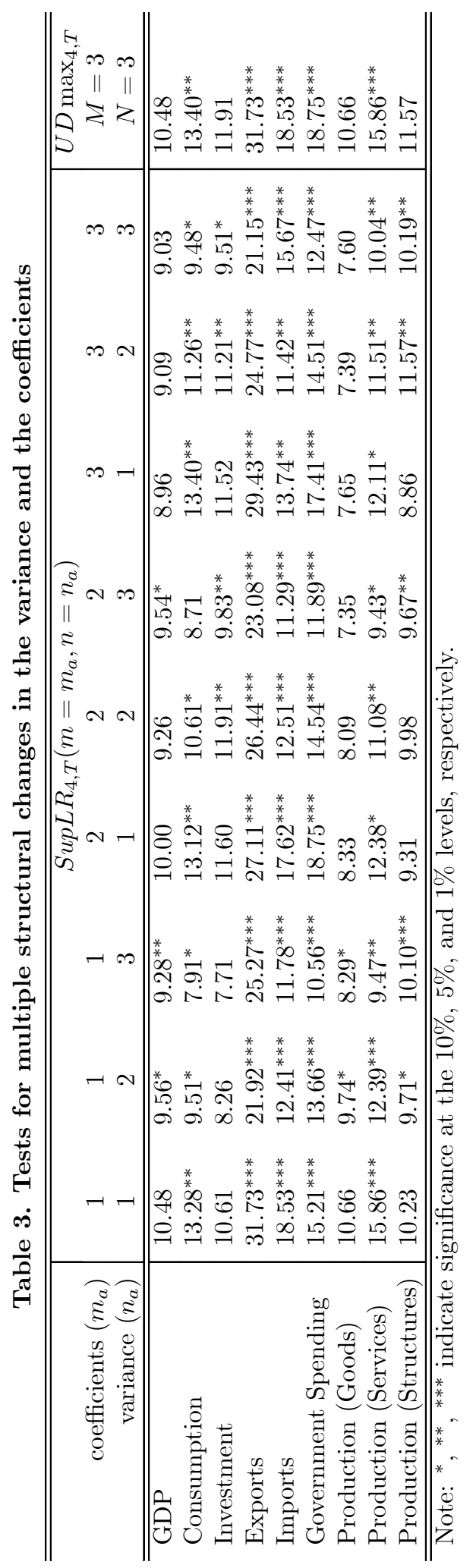


Table 4. Tests for multiple structural changes in the variance of the errors

\begin{tabular}{|c|c|c|c|c|c|c|c|c|}
\hline \multirow{3}{*}{$\begin{array}{r}\text { variance }\left(n_{a}\right) \\
\text { coefficients }\left(m_{a}\right) \\
\end{array}$} & \multicolumn{8}{|c|}{$\operatorname{SupLR}_{2, T}\left(n=n_{a} \mid m=m_{a}\right)$} \\
\hline & 1 & 1 & 1 & 1 & 2 & 2 & 2 & 2 \\
\hline & 0 & 1 & 2 & 3 & 0 & 1 & 2 & 3 \\
\hline GDP & $15.90^{* * *}$ & $13.75^{* * *}$ & $12.37^{* *}$ & $10.75^{* *}$ & $10.64^{* * *}$ & $10.28^{* * *}$ & $10.42^{* * *}$ & 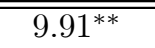 \\
\hline Consumption & $18.19^{* * *}$ & $17.29^{* * *}$ & $14.05^{* * *}$ & $15.82^{* * *}$ & $9.96^{* *}$ & $9.49^{* *}$ & $7.69^{*}$ & $9.33^{* *}$ \\
\hline Investment & $8.17^{*}$ & 6.53 & 5.82 & 7.18 & 5.99 & 5.34 & $7.55^{*}$ & $7.07^{*}$ \\
\hline Exports & $7.52^{*}$ & 5.98 & $9.22^{* *}$ & $17.04^{* * *}$ & 6.27 & 5.46 & $7.81^{*}$ & $11.06^{* * *}$ \\
\hline Imports & $12.87^{* *}$ & $18.14^{* * *}$ & $16.00^{* * *}$ & $18.82^{* * *}$ & $8.21^{* *}$ & $10.73^{* * *}$ & $9.97^{* *}$ & $11.40^{* * *}$ \\
\hline Government Spending & $22.20^{* * *}$ & $18.63^{* * *}$ & $16.36^{* * *}$ & $17.38^{* * *}$ & $12.79^{* * *}$ & $14.02^{* * *}$ & $9.17^{* *}$ & $10.99^{* * *}$ \\
\hline Production (Goods) & $7.61^{*}$ & $13.65^{* * *}$ & $9.13^{* *}$ & 5.89 & 6.49 & $11.63^{* * *}$ & $8.20^{* *}$ & 6.84 \\
\hline Production (Services) & $17.59^{* * *}$ & $18.37^{* * *}$ & $22.34^{* * *}$ & $19.58^{* * *}$ & $13.30^{* * *}$ & $13.46^{* * *}$ & $16.17^{* * *}$ & $15.72^{* * *}$ \\
\hline \multirow[t]{2}{*}{ Production (Structures) } & 6.76 & 6.93 & 2.88 & 1.09 & $7.72^{*}$ & $7.91^{*}$ & $7.38^{*}$ & $9.65^{* *}$ \\
\hline & \multicolumn{4}{|c|}{$\overline{\overline{S u p L R} R_{2, T}\left(n=n_{a} \mid m=m_{a}\right)}$} & \multicolumn{4}{|c|}{$\overline{U D \max _{2 T}\left(N, m=m_{a}\right)}$} \\
\hline variance $\left(n_{a}\right)$ & 3 & 3 & 3 & 3 & $N=3$ & $N=3$ & $N=3$ & $N=3$ \\
\hline coefficients $\left(m_{a}\right)$ & 0 & 1 & 2 & 3 & 0 & 1 & 2 & 3 \\
\hline GDP & $8.37^{* *}$ & $8.81^{* * *}$ & $9.35^{* * *}$ & $8.95^{* * *}$ & $15.90^{* * *}$ & $13.76^{* * *}$ & $12.37^{* *}$ & $10.75^{* *}$ \\
\hline Consumption & $7.46^{* *}$ & $7.20^{* *}$ & 5.44 & $6.42^{*}$ & $18.19^{* * *}$ & $17.29^{* * *}$ & $14.05^{* * *}$ & $15.82^{* * *}$ \\
\hline Investment & 5.21 & 5.11 & 5.60 & 4.93 & $8.17^{*}$ & 6.53 & 7.55 & 7.18 \\
\hline Exports & 5.07 & $8.22^{* *}$ & $7.07^{* *}$ & $7.85^{* *}$ & 7.52 & $8.22^{*}$ & $9.22^{*}$ & $17.04^{* * *}$ \\
\hline Imports & $6.17^{*}$ & $8.33^{* *}$ & $7.50^{* *}$ & $8.45^{* * *}$ & $12.87^{* * *}$ & $18.14^{* * *}$ & $16.00^{* * *}$ & $18.82^{* * *}$ \\
\hline Government Spending & $9.05^{* * *}$ & $9.75^{* * *}$ & $6.87^{* *}$ & $7.80^{* *}$ & $22.20^{* * *}$ & $18.63^{* * *}$ & $16.36^{* * *}$ & $17.38^{* * *}$ \\
\hline Production (Goods) & 5.80 & $9.36^{* * *}$ & $7.20^{* *}$ & $7.08^{* *}$ & 7.61 & $13.65^{* * *}$ & $9.13^{*}$ & 7.08 \\
\hline Production (Services) & $9.26^{* * *}$ & $9.30^{* * *}$ & $11.49^{* * *}$ & $11.05^{* * *}$ & $17.59^{* * *}$ & $18.37^{* * *}$ & $22.34^{* * *}$ & $19.58^{* * *}$ \\
\hline Production (Structures) & $8.44^{* * *}$ & $8.18^{* *}$ & $7.00^{* *}$ & $7.50^{* *}$ & $8.44^{*}$ & $8.18^{*}$ & 7.38 & $9.65^{* *}$ \\
\hline
\end{tabular}

Notes: $1 .{ }^{*},{ }^{* *},{ }^{* * *}$ indicate significance at the $10 \%, 5 \%$, and $1 \%$ levels, respectively.

2. The $S u p L R_{2, T}$ test and the $U D \max _{2, T}$ test reduce to the $S u p L R_{1, T}$ test and the $U D \max _{1, T}$ test, respectively when $m_{a}=0$.

Table 5. Sequential tests for structural changes in the variance of the errors

\begin{tabular}{|c|c|c|c|c|c|}
\hline \multirow{3}{*}{$\begin{array}{r}\text { variance }\left(n_{a}\right) \\
\text { coefficients }\left(m_{a}\right)\end{array}$} & \multicolumn{4}{|c|}{$\operatorname{SupLR}_{10, T}\left(n=n_{a}+1 \mid n=n_{a}, m=m_{a}\right)$} & \multirow{3}{*}{$\begin{array}{l}\text { Number } \\
\text { of Breaks }\end{array}$} \\
\hline & 0 & 1 & 2 & 3 & \\
\hline & 3 & 3 & 3 & 3 & \\
\hline GDP & $14.04^{* * *}$ & $11.46^{* *}$ & 4.52 & 2.72 & 2 \\
\hline Consumption & $22.89^{* * *}$ & 3.71 & 3.62 & 3.62 & 1 \\
\hline Investment & $8.70^{*}$ & 8.35 & 8.35 & 0.88 & 1 \\
\hline Exports & $14.13^{* * *}$ & 7.87 & 7.87 & 7.87 & 1 \\
\hline Imports & $17.03^{* * *}$ & 4.02 & 4.02 & 4.02 & 1 \\
\hline Government Spending & $19.33^{* * *}$ & 3.96 & 4.83 & 1.94 & 1 \\
\hline Production (Goods) & $12.79^{* *}$ & $10.87^{* *}$ & 3.96 & 2.38 & 2 \\
\hline Production (Services) & $27.88^{* * *}$ & 8.30 & 3.69 & 4.57 & 1 \\
\hline Production (Structures) & 6.41 & $11.84^{* *}$ & 3.30 & 5.51 & 0 \\
\hline
\end{tabular}

Notes: Same as in Table 3. 
Table 6. Tests for multiple structural changes in the coefficients

\begin{tabular}{|c|c|c|c|c|c|c|c|c|}
\hline \multirow{3}{*}{$\begin{array}{r}\text { coefficients }\left(m_{a}\right) \\
\text { variance }\left(n_{a}\right) \\
\end{array}$} & \multicolumn{8}{|c|}{$\overline{\operatorname{SupLR}_{3, T}\left(m=m_{a} \mid n=n_{a}\right)}$} \\
\hline & 1 & 1 & 1 & 1 & 2 & 2 & 2 & 2 \\
\hline & 0 & 1 & 2 & 3 & 0 & 1 & 2 & 3 \\
\hline GDP & 8.27 & 2.71 & 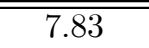 & 12.38 & (5.50 & 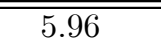 & 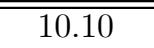 & 13.70 \\
\hline Consumption & 8.94 & 9.00 & 9.16 & 10.74 & 7.01 & 13.05 & 12.94 & 11.14 \\
\hline Investment & 16.01 & 12.72 & 9.69 & 9.78 & 8.04 & 14.13 & $18.80^{* *}$ & 14.46 \\
\hline Exports & $78.89^{* * *}$ & $50.36^{* * *}$ & $35.04^{* *}$ & $46.60^{* * *}$ & $23.57^{* * *}$ & $38.79^{* * *}$ & $33.20^{* * *}$ & $29.04^{* * *}$ \\
\hline Imports & $46.24^{* * *}$ & $33.35^{* * *}$ & $22.92^{* *}$ & $23.73^{* * *}$ & $19.12^{* * *}$ & $27.25^{* * *}$ & $21.22^{* * *}$ & $19.06^{* * *}$ \\
\hline Government Spending & $18.45^{*}$ & 9.78 & 15.46 & 14.54 & 9.87 & $15.99^{*}$ & 14.52 & 14.95 \\
\hline Production (Goods) & 10.54 & 16.45 & $18.05^{*}$ & 12.61 & 5.41 & 10.27 & 10.36 & 9.86 \\
\hline Production (Services) & 15.09 & 13.46 & 6.82 & 7.13 & 6.01 & 12.08 & 11.83 & 12.28 \\
\hline \multirow[t]{2}{*}{ Production (Structures) } & 14.75 & 12.76 & 10.05 & 13.99 & 8.16 & 10.66 & 11.21 & 10.69 \\
\hline & \multicolumn{4}{|c|}{$\operatorname{SupLR}_{3, T}\left(m=m_{a} \mid n=n_{a}\right)$} & \multicolumn{4}{|c|}{$\overline{U U \operatorname{Umax}_{3, T}\left(M, n=n_{a}\right)}$} \\
\hline coefficients $\left(m_{a}\right)$ & 3 & 3 & 3 & 3 & $M=3$ & $M=3$ & $M=3$ & $M=3$ \\
\hline variance $\left(n_{a}\right)$ & 0 & 1 & 2 & 3 & 0 & 1 & 2 & 3 \\
\hline "GDP & 3.86 & $\overline{c 6.69}$ & 8.85 & 11.79 & 8.27 & 6.69 & 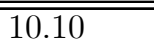 & 13.70 \\
\hline Consumption & 3.98 & $14.38^{*}$ & $15.49^{* *}$ & 14.05 & 8.94 & 14.38 & 15.49 & 14.05 \\
\hline Investment & 4.74 & 13.96 & $15.38^{* *}$ & 12.37 & 16.01 & 14.13 & $18.80^{* *}$ & 14.46 \\
\hline Exports & 11.90 & $39.47^{* * *}$ & $33.77^{* * *}$ & $28.23^{* * *}$ & $78.89^{* * *}$ & $50.36^{* * *}$ & $35.05^{* * *}$ & $46.60^{* * *}$ \\
\hline Imports & 9.88 & $25.18^{* * *}$ & $21.48^{* * *}$ & $19.07^{* * *}$ & $46.24^{* * *}$ & $33.35^{* * *}$ & $22.92^{* *}$ & $23.73^{* * *}$ \\
\hline Government Spending & 5.92 & $14.75^{*}$ & $14.74^{*}$ & $14.66^{*}$ & $18.45^{*}$ & 15.99 & 15.46 & 14.95 \\
\hline Production (Goods) & 3.56 & 8.29 & 8.91 & 9.65 & 10.54 & 16.45 & $18.05^{*}$ & 12.61 \\
\hline Production (Services) & 4.05 & 11.82 & 12.46 & 13.03 & 15.09 & 13.46 & 12.46 & 13.03 \\
\hline Production (Structures) & 5.08 & 9.09 & $14.29^{*}$ & 11.86 & 14.75 & 12.76 & 14.29 & 13.99 \\
\hline
\end{tabular}

Notes: $1 .{ }^{*},{ }^{* *},{ }^{* * *}$ indicate significance at the $10 \%, 5 \%$, and $1 \%$ levels, respectively.

2. The $S u p L R_{3, T}$ test and the $U D \max _{3, T}$ test reduce to the standard $S u p L R$ test and the $U D \max$ LR test, respectively, when $n_{a}=0$ (see Andrews, 1993, and Bai and Perron, 1998).

Table 7. Sequential tests for structural changes in the coefficients

\begin{tabular}{l|cccc|c}
\hline \hline \multirow{2}{*}{$\begin{array}{c}\text { coefficients }\left(m_{a}\right) \\
\quad \text { variance }\left(n_{a}\right)\end{array}$} & \multicolumn{2}{|c|}{ SupLR $R_{9, T}\left(m=m_{a}+1 \mid m=m_{a}, n=n_{a}\right)$} & $\begin{array}{c}\text { Number } \\
\text { of Breaks }\end{array}$ \\
\hline \hline GDP & 14.08 & 3 & 3 & 3 & \\
Consumption & 10.76 & $20.916^{* *}$ & 11.48 & 12.47 & 0 \\
Investment & 13.80 & $25.29^{* * *}$ & 11.92 & 11.05 & 0 \\
Exports & $45.45^{* * *}$ & 11.54 & $37.00^{* * *}$ & 11.20 & 0 \\
Imports & $31.94^{* * *}$ & 18.04 & 16.54 & 19.39 & 1 \\
Government Spending & 16.40 & 17.31 & 17.31 & 16.44 & 0 \\
Production (Goods) & 12.58 & 8.39 & 9.13 & 10.02 & 0 \\
Production (Services) & 8.15 & 13.98 & 12.21 & 10.84 & 0 \\
Production (Structures) & 11.34 & 12.00 & 19.18 & 6.73 & 0 \\
\hline \hline
\end{tabular}

Notes: Same as in Table 3. 


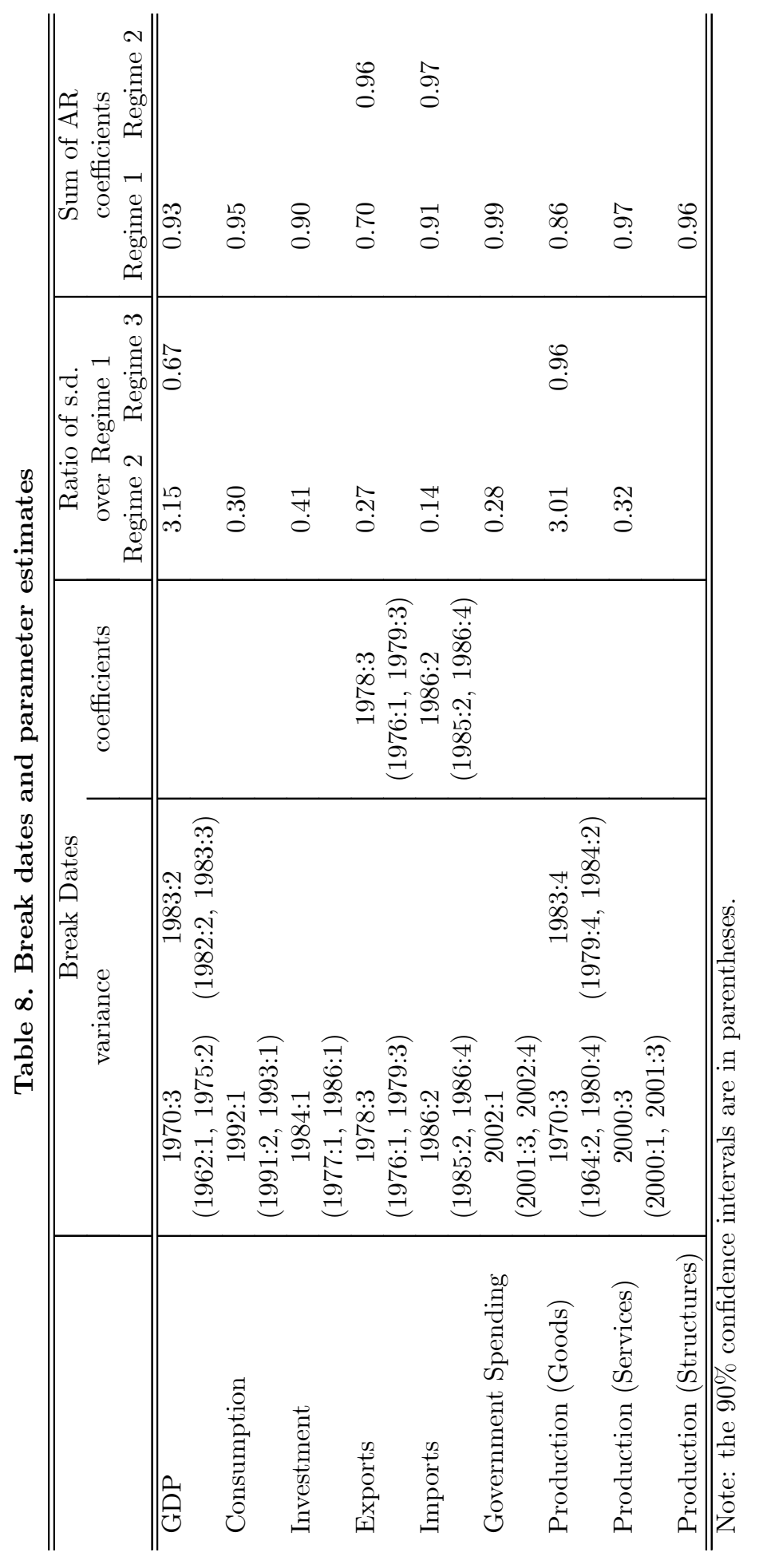


Figure 1. Trend and cycle decomposition of U.S. real GDP and its components.

\section{GDP}
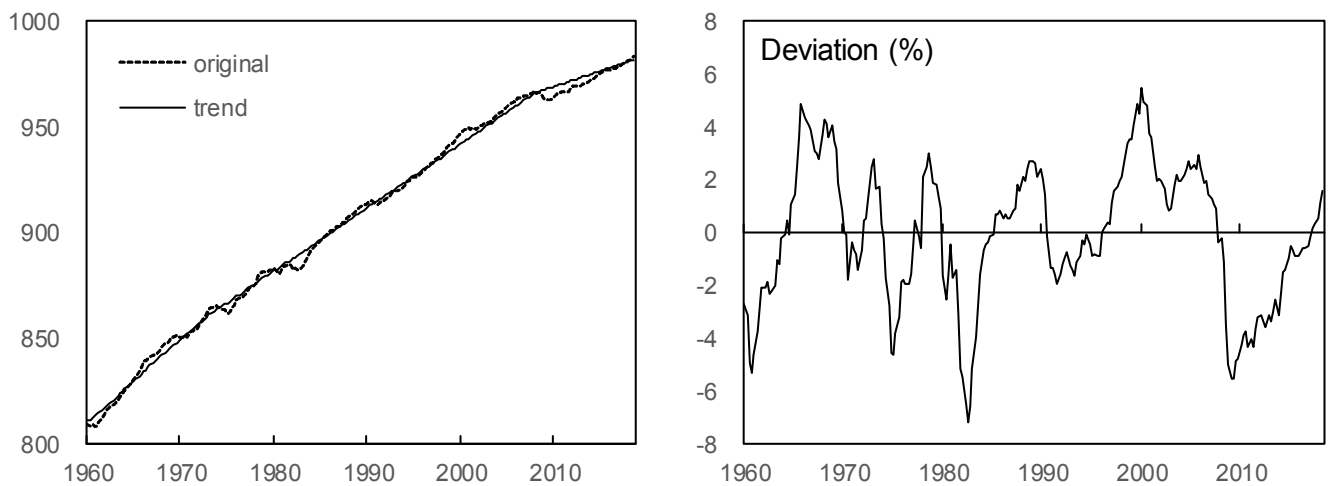

\section{Consumption}
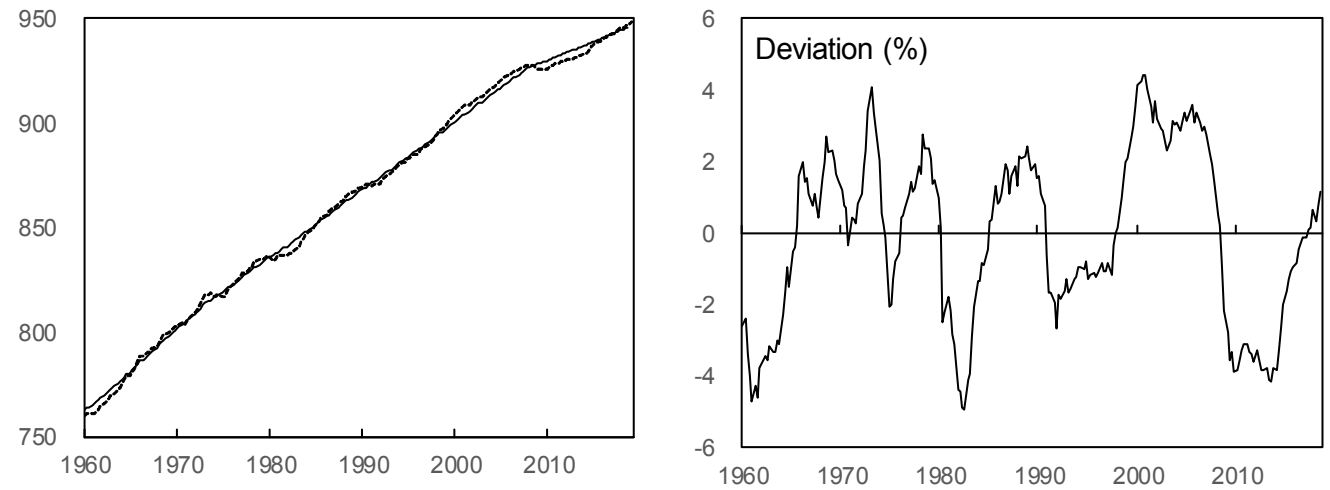

Investment
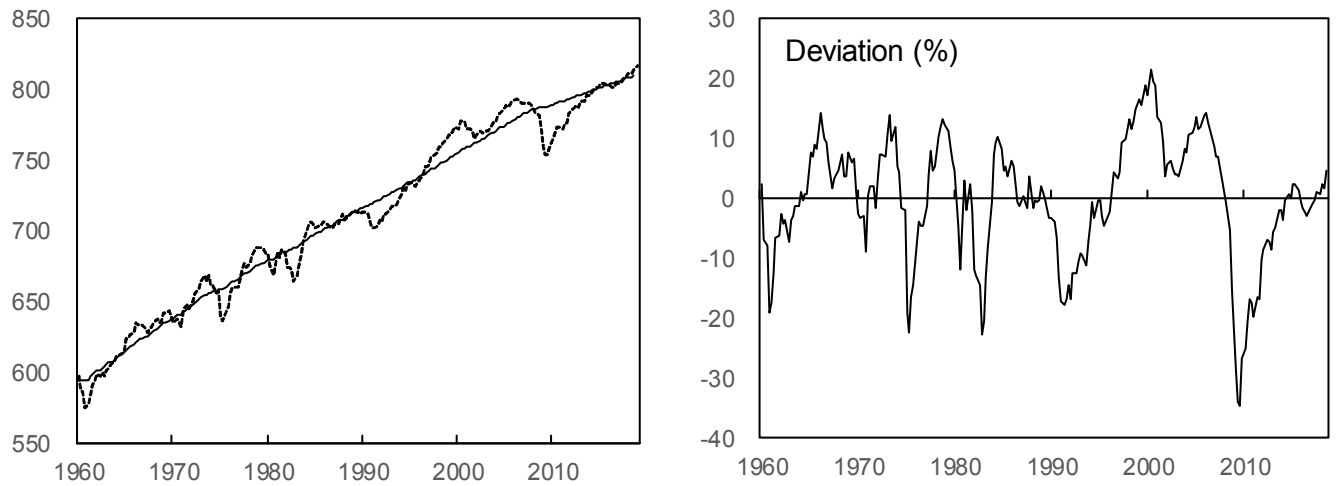
Figure 1. Trend and cycle decomposition of U.S. real GDP and its components (continued).

\section{Exports}
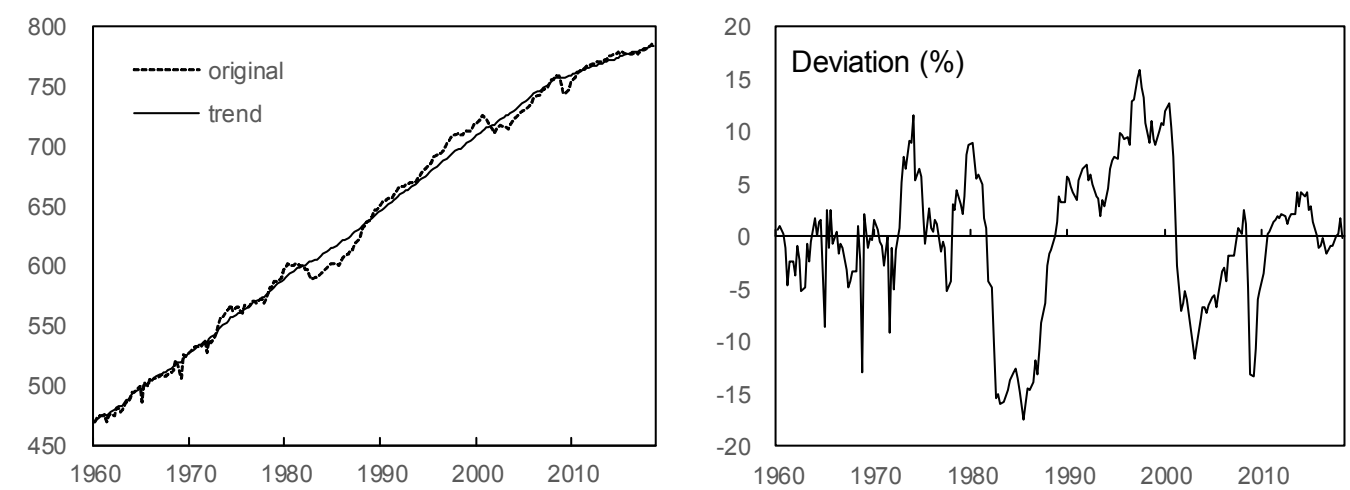

Imports
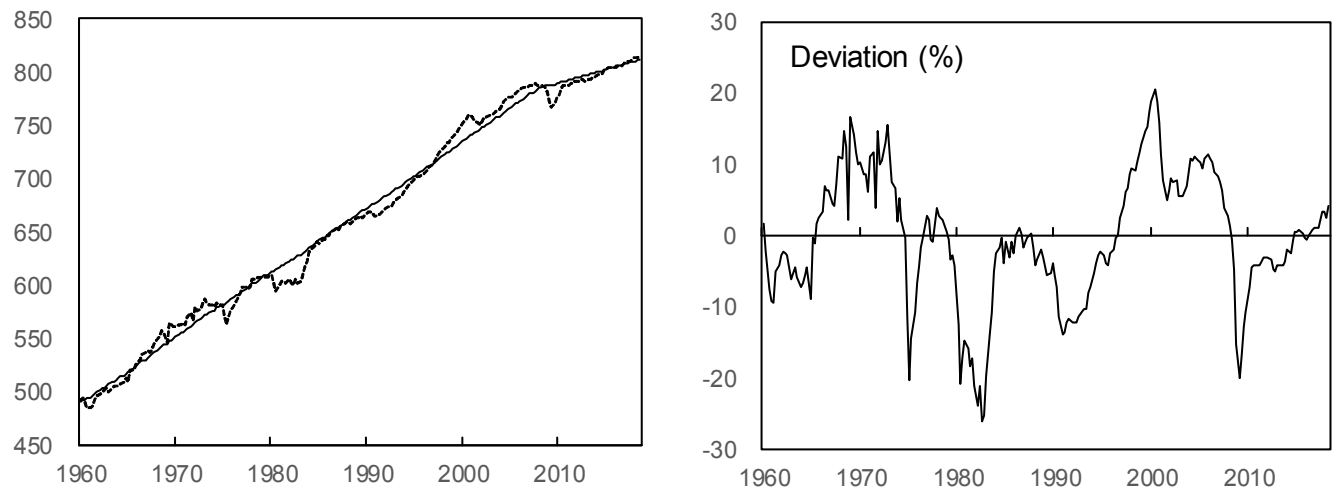

Government spending
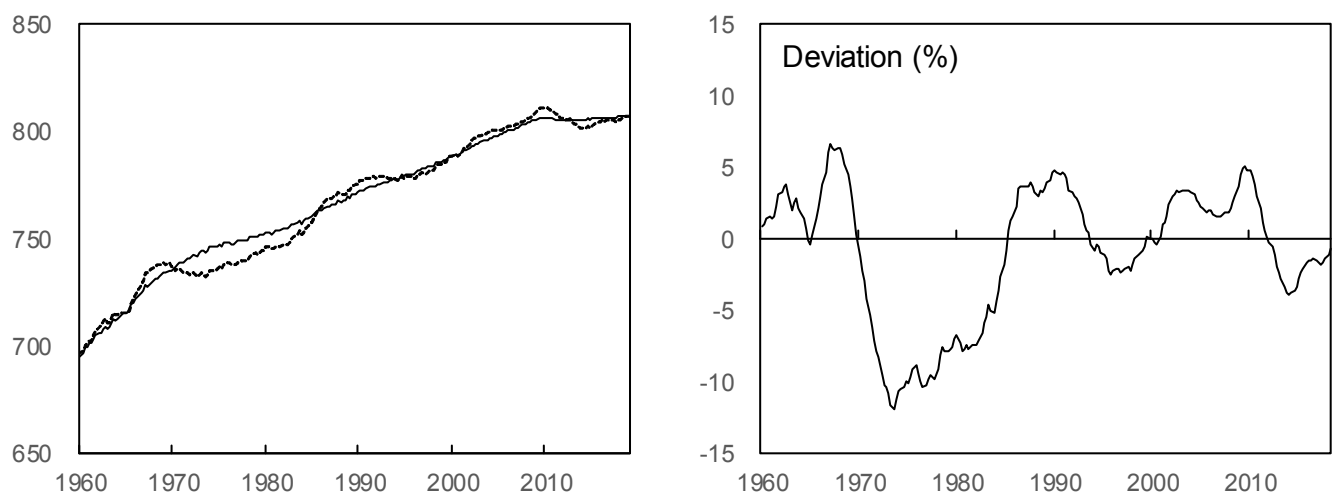
Figure 1. Trend and cycle decomposition of U.S. real GDP and its components (continued).

Production (goods)
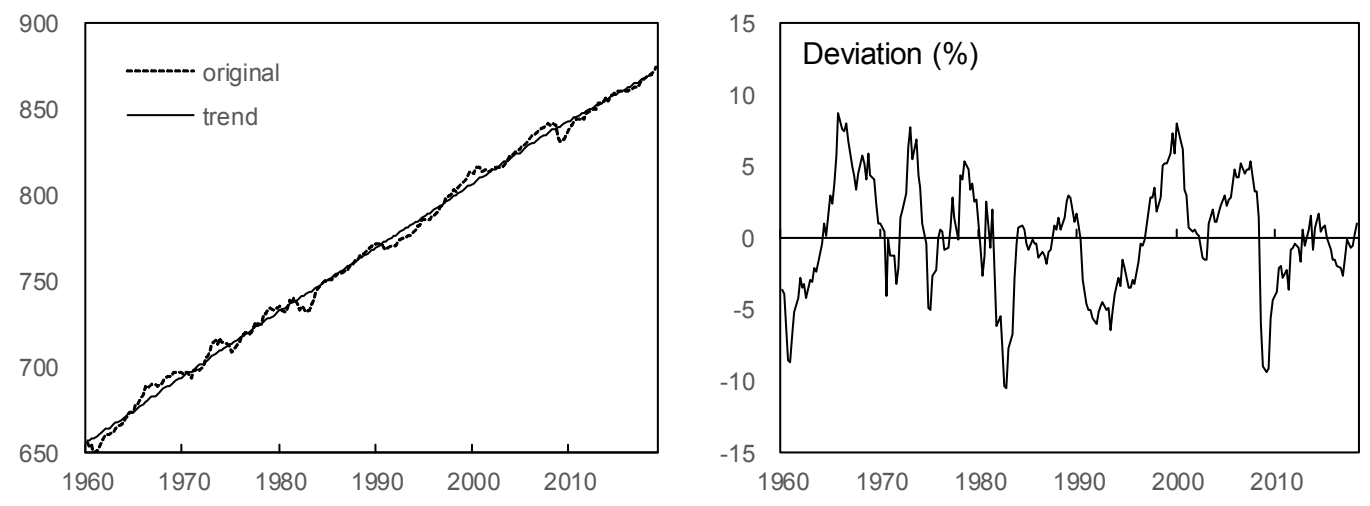

Production (services)
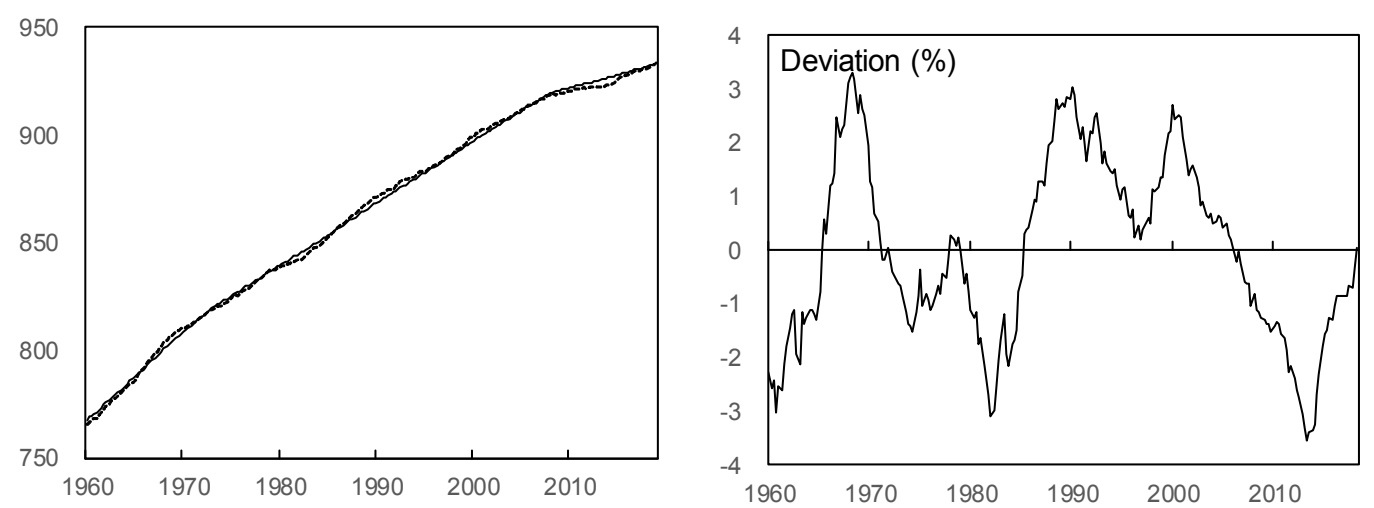

Production (structures)
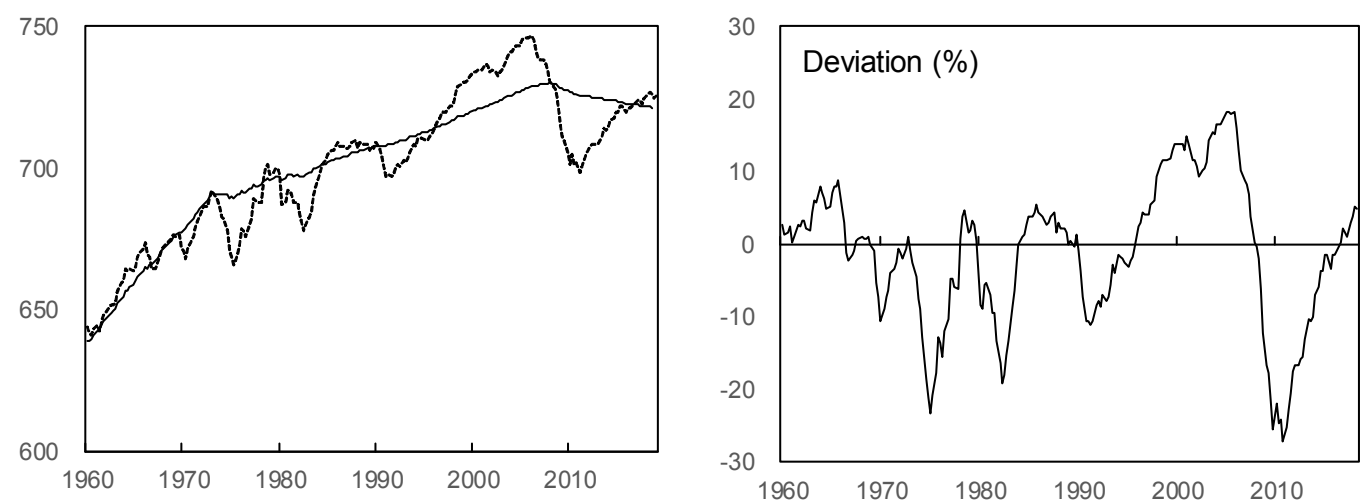
Figure 2. Cyclical component and the growth rate of the stochastic trend $\left(\eta_{t}\right)$ for Government Spending

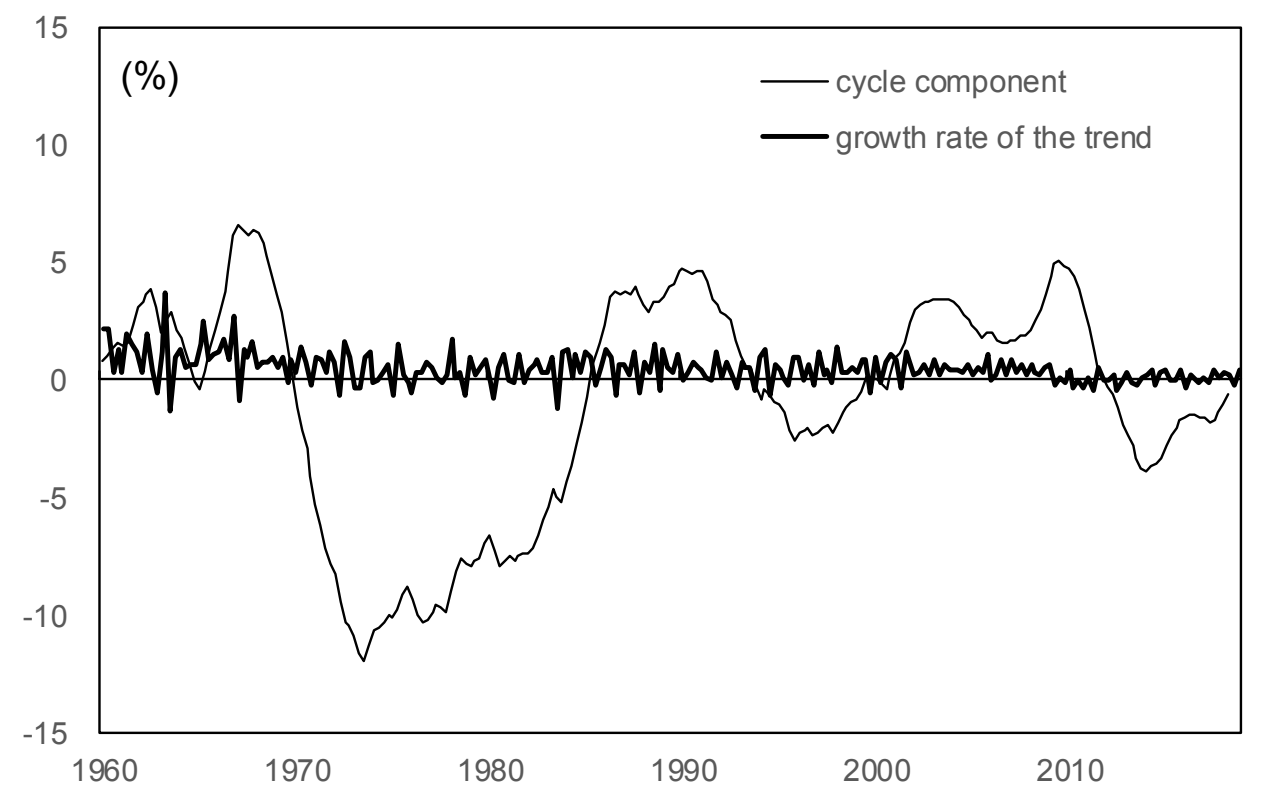

